\title{
The USA National Phenology Network- Taking the Pulse of Our Planet
}

\section{What is Phenology?}

Phenology is derived from the Greek word "phaino," meaning to show or appear, and has two usages. First, phenology refers to recurring plant and animal life-cycle stages, such as leafing and flowering, maturation of agricultural plants, emergence of insects, and migration of birds. It can also refer to the study of these recurring plant and animal life-cycle stages, especially their timing and relationships with weather and climate.

Phenology, put another way, is simply nature's calendar- when cherry trees blossom, when robins build their nests, when salmon swim upstream to spawn, or when leaves turn colors in the fall.

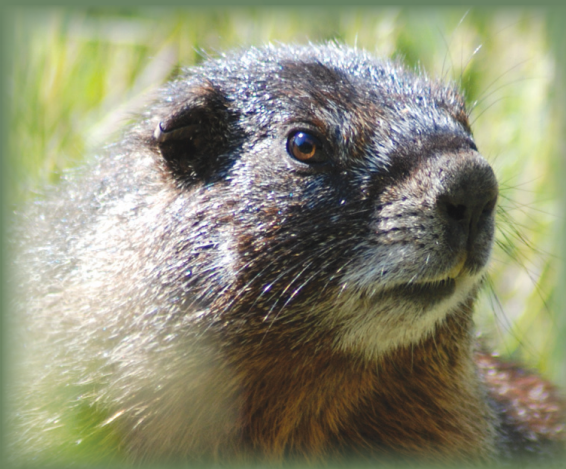

Phenology and population size of the yellow-bellied marmot are sensitive to climate variation in Colorado. Photograph by Abraham Miller-Rushing, National Park Service.
People have tracked phenology for centuries and for the most practical reasons: it helped them know when to hunt and fish, when to plant and harvest crops, and when to navigate waterways. Now phenology is being used as a tool to assess climate change and its effects on both natural and modified ecosystems.

How is the timing of events in plant and animal life cycles, like flowering or migration, responding to climate change? And how are those responses, in turn, affecting people and ecosystems?

The USA National Phenology Network (the Network) is working to answer these questions for science and society by promoting a broad understanding of plant and animal phenology and their relationship to environmental change. The Network is a consortium of organizations and individuals that collect, share, and use phenology data, models, and related information to enable scientists, resource managers, and the public to adapt in response to changing climates and environments. In addition, the Network encourages people of all ages and backgrounds to observe and record phenology as a way to discover and explore the nature and pace of our dynamic world.

The National Coordinating Office (NCO) of the Network is a resource center that facilitates and encourages widespread collection, integration, and sharing of phenology data and related information (for example, meteorological and hydrological data). The NCO develops and promotes standardized methods for field data collection and maintains several online user interfaces for data upload and download, as well as data exploration, visualization, and analysis. The NCO also facilitates basic and applied research related to phenology, the development of decision-support tools for resource managers and planners, and the design of educational and outreach materials and programs.

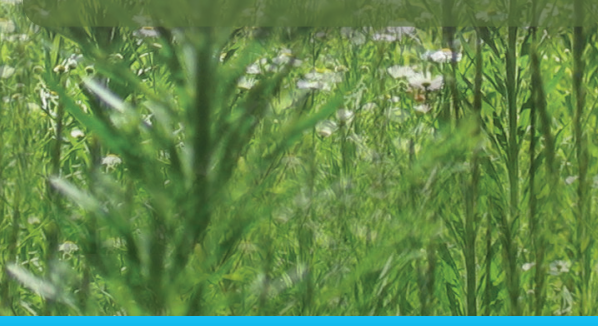

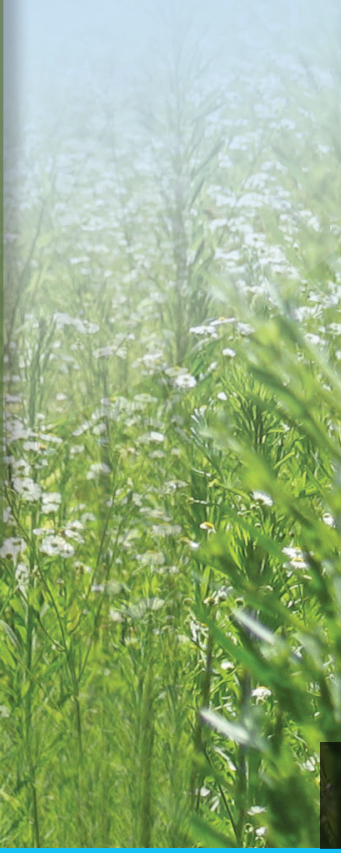

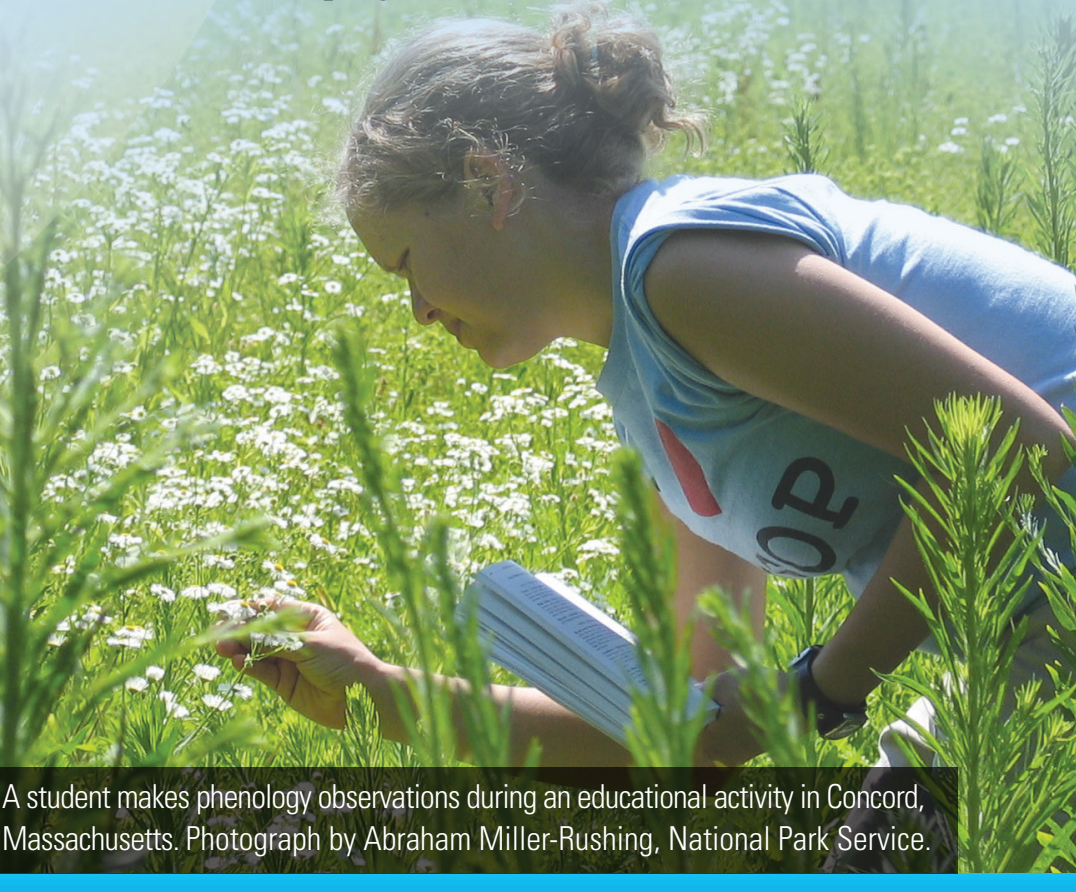




\section{Allergy Watch}

Changes in phenology affect human health by changing timing and patterns of allergy seasons. The Network is collaborating with many partners on a new project to predict the timing of human allergic reactions caused by juniper pollen. Researchers intend to integrate data from citizen scientist observers of juniper phenology, satellite images of tree green-up, and data from health centers to better understand the dynamics of seasonal allergies. Better forecasting of environmental triggers can lead to more effective public health measures and, consequently, improved quality of life for seasonal allergy sufferers.

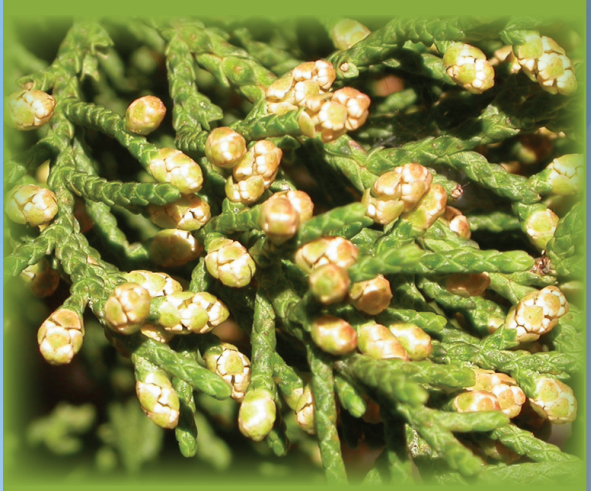

Pollen cones on an Ashe's Juniper before they have released their pollen. Photograph by Estelle Levetin, University of Tulsa.

\section{Getting Involved}

\section{nature's,
notebook \\ A project of the USA-NPN}

\section{Observers Collecting Phenology Data}

Both professional and "citizen" scientists are encouraged by the Network to collect observations of plant and animal phenology and to report them through Nature's Notebook, an online user interface for data entry and visualization. Contemporary data collected through Nature's Notebook and some of our partner projects are integrated and used to inform decisionmaking in a variety of contexts, including agriculture, drought monitoring, and wildfire risk assessment. Phenological information is also critical for the management of wildlife, invasive species, and agricultural pests, and for understanding and managing risks to human health and welfare, including allergies, asthma, and vector-borne diseases. Visit the Network's website to learn more and sign up to become an observer.

\section{Discovering and Organizing Historical Datasets}

Because phenological changes can take decades to detect, the Network also seeks to find and share historical phenology datasets. These valuable data sources can range from records of migratory duck arrivals to a backyard pond to oral histories of when to plant vegetables. For example, Aldo Leopold, Thomas Jefferson, and Lewis and Clark all recorded phenology information in their diaries or record books. Scientists have recently used phenological information collected by Henry David Thoreau to examine patterns of change in plant phenology in areas around Concord, Massachusetts (see "Survival SecretFlexible Phenology" sidebar). If you have or know about a historical dataset, consider submitting basic information about it to the Network dataset registry tool on our website.
To become an observer, learn more about phenology, participate in the juniper pollen project, explore possibilities for partnerships, or submit information about a historical dataset, visit www.usanpn.org 


\section{Building Effective Partnerships}

\section{Partners}

The Network is a group of partners and collaborators, including scientists, educators, natural resource managers, public agencies, nongovernmental organizations, specialized monitoring or science networks, and Native American tribes working together to collect, interpret, and use phenology data and related information. Effective partnerships are critical to the success of the Network. If your organization, agency, or program is interested in working with us, please visit our website or contact us directly. We are enthusiastic to collaborate with educators, researchers, and citizen scientist networks, as well as Federal, state, and local organizations.

\section{A Key Partner-The Great Sunflower Project}

The Great Sunflower Project, a citizen science initiative based at San Francisco State University, is one of the Network's many beneficial partnerships. Participants in the Great Sunflower Project monitor and record bee visitation to sunflowers planted in their gardens. They are also encouraged to record the phenology of their sunflowers as they emerge from the soil, produce leaves, and flower. Plant and bee phenology data collected jointly through this partnership generate important information that contributes to our understanding of the relationships between plants and their pollinators.

\section{Survival Secret-Flexible Phenology}

When researchers returned to Henry David Thoreau's journals and searched for the plants he had observed 150 years ago, they found that many of the species had declined or disappeared entirely from Walden Pond and the town of Concord, Massachusetts. Researchers found that the surviving species had one thing in common: their flowering times tracked the warming temperatures observed over the past 150 years. Conservation and management have traditionally focused on the geographic distributions of plants and animals, but emerging research shows that the timing of life cycle events may be equally important for predicting responses to climate change and informing management practices.

\section{Making the Connection - Red Knots and \\ Horseshoe Crabs}

Each breeding season, horseshoe crabs arrive at their Atlantic Coast spawning sites in the hundreds of thousands, with each female laying approximately 90,000 eggs. The red knot, a migratory shorebird, relies on this abundant but temporary food source to survive its long journey north. Climate change may have already altered the environmental cues that cause the horseshoe crabs and red knots to arrive simultaneously. This potential ecological mismatch would have detrimental effects on the population of red knots.

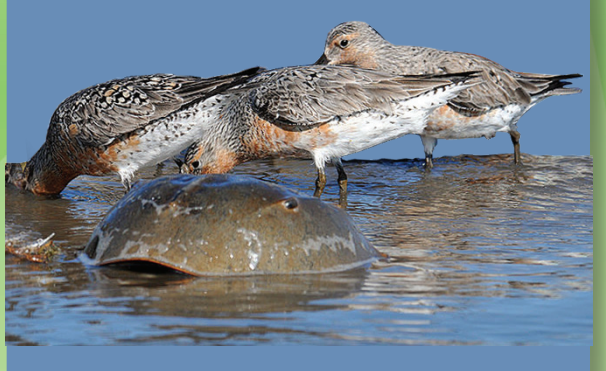

Red knots feeding on horseshoe crab eggs in Delaware Bay at Mispillion Harbor Reserve, Delaware. Photograph by Gregory Breese, U.S. Fish and Wildlife Service. 


\section{Pollination and Phenology}

Pollination by native insects contributes more than $\$ 3$ billion in agricultural crops each year. Climate-driven changes in the phenology of crops and native insects could change the effectiveness of insect pollination for the better or for the worse. However, we know very little about how pollinator phenology is changing, which makes it difficult to predict how crops will be affected and how farmers might best adapt their management practices. By collecting observations of insect phenology and crop phenology together, the Network is contributing to our understanding of the changes taking place and helping to ensure the viability of crops across the country.

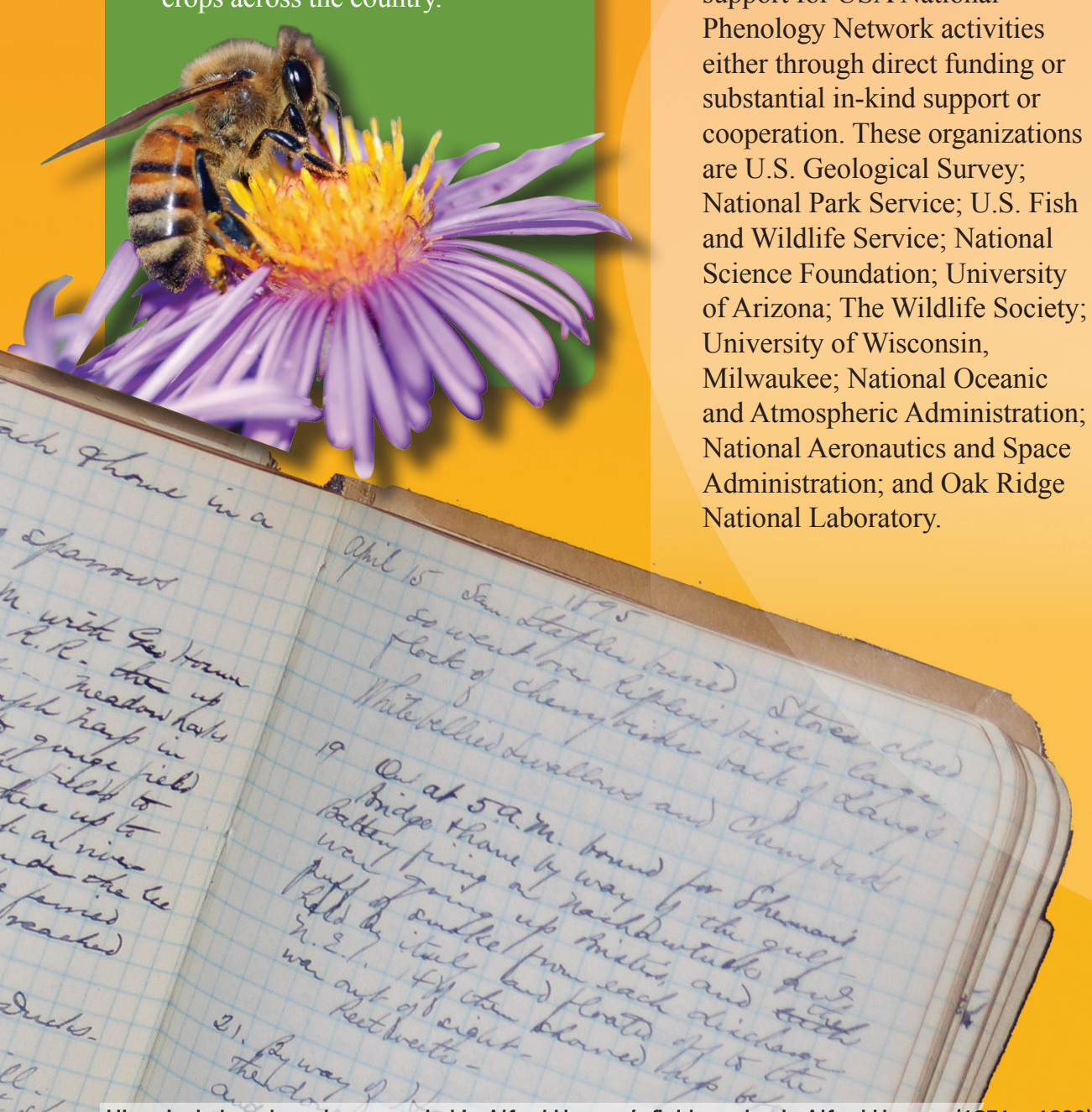

frue Historical phenology data recorded in Alfred Hosmer's field notebook. Alfred Hosmer (1851 - 1903) was a naturalist and early follower of Thoreau. Photograph by Richard Primack, Boston University.

\section{Our Cooperators}

The organizations whose logos appear below provide support for USA National Phenology Network activities either through direct funding or cooperation. These organizations are U.S. Geological Survey; National Park Service; U.S. Fish and Wildlife Service; National Science Foundation; University of Arizona; The Wildlife Society; University of Wisconsin Milwaukee; National Oceanic Administration; and Oak Ridge National Laboratory.

\section{Education and Outreach-Communicating Climate Change Through the Seasons}

Phenology is a great way to teach students and learners of all ages about the life cycles of plants and animals and to create a tangible understanding of climate change. For example, Network partners in southern California have established over a dozen phenology observation gardens and are recording times of leaf emergence, flowering, fruiting, and seed dispersal. These gardens are funded and managed by diverse organizations such as the U.S. Fish and Wildlife Service, Boys \& Girls Clubs of America, and several nature centers. The NCO facilitates the development of partnerships like these, and it supports them by providing the blueprint for the observation gardens as well as the scientific framework for collecting phenology data. Participating students interact with undergraduate students and researchers at the University of California, Santa Barbara, and can compare their results to long-term historical records like those kept in herbarium collections. This project not only provides an opportunity for students to learn more about plants and animals, but it also allows them to gain an understanding about climate change and what it means to be a scientist.
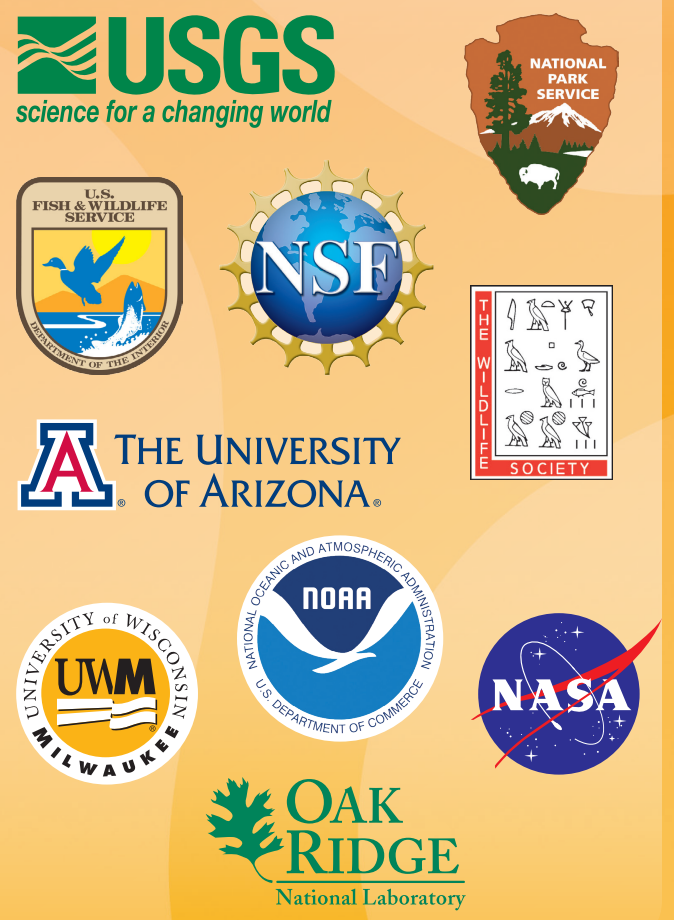

For further information please contact:

Jake F. Weltzin, Executive Director USA National Phenology Network

National Coordinating Office 1955 East 6th Street Tucson, AZ 85721 520-626-3821 www.usanpn.org nco@usanpn.org

This Fact Sheet and any updates to it are available online at http://pubs.usgs.gov/ fs/2011/3023 